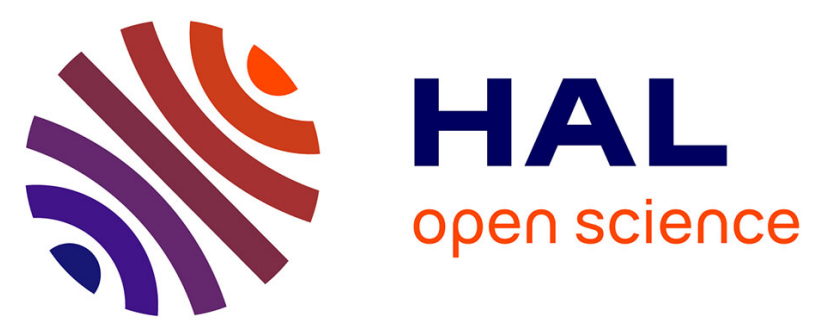

\title{
Metabolism and genotoxicity of polycyclic aromatic hydrocarbons in human skin explants: mixture effects and modulation by sunlight
}

Anne von Koschembahr, Antonia Youssef, David Béal, Etienne Bourgart, Alex Rivier, Marie Marques, Marie-Thérèse Leccia, Jean-Philippe Giot, Anne Maitre, Thierry Douki

\section{To cite this version:}

Anne von Koschembahr, Antonia Youssef, David Béal, Etienne Bourgart, Alex Rivier, et al.. Metabolism and genotoxicity of polycyclic aromatic hydrocarbons in human skin explants: mixture effects and modulation by sunlight. Archives of Toxicology, 2020, 94, pp.495-507. 10.1007/s00204019-02650-z . hal-02439056

\section{HAL Id: hal-02439056 https://hal.science/hal-02439056}

Submitted on 14 Jan 2020

HAL is a multi-disciplinary open access archive for the deposit and dissemination of scientific research documents, whether they are published or not. The documents may come from teaching and research institutions in France or abroad, or from public or private research centers.
L'archive ouverte pluridisciplinaire HAL, est destinée au dépôt et à la diffusion de documents scientifiques de niveau recherche, publiés ou non, émanant des établissements d'enseignement et de recherche français ou étrangers, des laboratoires publics ou privés. 


\section{Metabolism and genotoxicity of polycyclic aromatic hydrocarbons in human skin explants: mixture effects and modulation by sunlight}

Anne von Koschembahr ${ }^{1}$, Antonia Youssef ${ }^{1}$, David Béal ${ }^{1}$, Etienne Bourgart ${ }^{2}$, Alex Rivier ${ }^{2}$, Marie Marques $^{2}$, Marie-Thérèse Leccia ${ }^{3}$, Jean-Philippe Giot ${ }^{4}$, Anne Maitre $^{2}$ and Thierry Douki ${ }^{1, *}$

${ }^{1}$ Univ. Grenoble Alpes, UGA, CEA, CNRS, IRIG, SyMMES, F-38000 Grenoble

${ }^{2}$ Equipe EPSP Environnement et Prédiction de la Santé des Populations-laboratoire TIMCIMAG (UMR 5525 UGA-CNRS), Université Grenoble Alpes, Faculté de Médecine, La Tronche, France

3 Service de Dermatologie, Allergologie et Photobiologie, Centre Hospitalier Universitaire Grenoble Alpes, La Tronche, France

${ }^{4}$ Service de Chirurgie Plastique et Maxillo-faciale, Centre Hospitalier Universitaire Grenoble Alpes, La Tronche, France

*Corresponding author: Thierry Douki (ORCID 0000-0002-5022-071X)

IRIG/SyMMES/CIBEST, UMR 5819 CEA-UGA-CNRS

CEA-Grenoble

17 avenue des Martyrs

38054 Grenoble Cedex 9

France

Telephone: +3343878 3191

Fax: +3343878 5090

Email: thierry.douki@cea.fr 


\section{Abstract}

Cutaneous exposure to carcinogenic polycyclic aromatic hydrocarbons (PAH) occurs frequently in the industrialized workplace. In the present study, we addressed this topic in a series of experiments using human skin explants and organic extracts of relevant industrial products. PAH mixtures were applied topically in volumes containing either 10 or $1 \mathrm{nmol} \mathrm{B}[\mathrm{a}] \mathrm{P}$. We first observed that although mixtures were very efficient at inducing expression of CYP450 $1 A 1,1 A 2$, and $1 B 1$, formation of adducts of PAH metabolites to DNA, like those of benzo[a]pyrene diol epoxide (BPDE), was drastically reduced as the complexity of the surrounding matrix increased. Interestingly, observation of a nonlinear, dose-dependent response with the least complex mixture suggested the existence of a threshold for this inhibitory effect. We then investigated the impact of simulated sunlight (SSL) on the effects of PAH in skin. SSL was found to decrease the expression of CYP450 genes when applied either after or more efficiently before PAH treatment. Accordingly, the level of DNA-BPDE adducts was reduced in skin samples exposed to both PAH and SSL. The main conclusion of our work is that both increasing chemical complexity of the mixtures and coexposure to UV radiation decreased the production of adducts between DNA and PAH metabolites. Such results must be taken into account in risk management.

Keywords: skin, polycyclic aromatic hydrocarbons, UV radiation, co-exposure, CYP450, DNA adducts 


\section{Introduction}

Polycyclic aromatic hydrocarbons $(\mathrm{PAH})$ are ubiquitous pollutants which represent a major concern in public health (IARC 2010). Due to their presence in polluted atmospheres (especially urban areas) and their abundance in food, PAH contaminate the general population by both inhalation and ingestion. PAH also represent a large fraction of the contaminants load in some occupational tasks (Boffetta et al. 1997; Deschamps et al. 2006; Forster et al. 2008). Indeed, PAH are produced by incomplete combustion of organic matter and are present not only in many industrial emission sources, but also in numerous carbon-containing materials used in various applications. These products include bitumen for road construction or carbon electrodes for electrolysis in aluminum or silicon factories. One specificity of occupational exposure is the importance of the cutaneous contamination route (Fustinoni et al. 2010; Herbert et al. 1990; VanRooij et al. 1993), which is typically negligible in the general population. As a consequence, skin is clearly identified as a target organ for PAH-induced carcinogenesis in exposed workers (Pukkala et al. 2014; Siddens et al. 2012). Another interesting group that may provide useful data on dermal exposure to PAH are patients suffering from skin diseases who are treated by coal tarcontaining ointments (Roelofzen et al. 2007), although PAH are not directly in contact with skin but rather mixed with a matrix. Like in all exposure scenarios, a main issue with PAH is the complexity and variability of the composition of the mixtures, which may contain dozens of products, the proportion of which varies from one source to the other. A much more typical characteristic that needs to be considered in the case of skin toxicity of PAH is the additional role of solar light (Dickel et al. 2016) that can induce photosensitization reaction and/or modulate metabolism of PAH. 
Metabolism in a key biological response of skin and other tissues in terms of toxicological impact of PAH (Baird et al. 2005; IARC 2010; Shimada and Fujii-Kuriyama 2004). Indeed, parent PAH are not reactive due to their highly stable aromatic structure. They are converted by phase I enzymes, such as cytochrome P450-dependent monooxygenases (CYP450), into reactive metabolites, which then undergo conjugation to water-soluble groups and eventual elimination. Unfortunately, a fraction of these phase I metabolites may diffuse in the cells and reach biomolecules, such as DNA where it binds to bases thereby producing DNA adducts (Jeffrey et al. 1977; Peltonen and Dipple 1995). An additional genotoxic pathway involves release of reactive oxygen species (Park et al. 2009; Tsuji et al. 2011), although this was found to be a minor process, at least in cultured human cell lines (Genies et al. 2013; Tarantini et al. 2009). Formation of adducts between PAH metabolites and DNA has been specifically investigated for benzo[a]pyrene (B[a]P). Numerous in vitro and in vivo works have provided large amounts of information on the biochemical pathways involved in the genotoxicity of this compound classified as carcinogenic to humans by IARC (IARC 2010). These investigations pointed the diol-epoxide derivative of B[a]P (BPDE) as the most deleterious metabolite (Jeffrey et al. 1977). DNA adducts of other PAH have also been identified, but they are less efficiently produced than those of $\mathrm{B}[\mathrm{a}] \mathrm{P}$. Expression of metabolism genes and formation of DNA adducts are well documented in skin exposed to $\mathrm{B}[\mathrm{a}] \mathrm{P}$ (Bickers et al. 1984; Darwiche et al. 2007; Siddens et al. 2012).

Although the genotoxic properties of individual PAH are understood, predicting the effects of the mixtures of these compounds is still a challenge (Jarvis et al. 2014). Use of Toxic Equivalency Factors, like for dioxins (Safe 1990), has been proposed for the prediction of the toxicity of complex exposures to PAH (Nisbet and LaGoy 1992). Unfortunately, this approach is based on an additivity principle that is contradicted by a growing amount of observations. This is the case for 
in vitro studies where both inhibitory and synergistic effects were observed, even for simple cases like binary mixtures (Binkova and Sram 2004; Genies et al. 2016; Jarvis et al. 2013; Staal et al. 2008; Tarantini et al. 2011b). The fact that the results are different from one cell type to another complicates the prediction. The toxic effects of binary and tertiary PAH mixtures in skin has been investigated in some animal studies. Both inhibitory and synergistic effects were observed on the formation of DNA adducts, depending on composition of the mixtures (Hughes and Phillips 1993; Rice et al. 1984; Smolarek et al. 1987). Studies of the impact of complex mixtures on genotoxicity of specific PAH in murine skin are also unclear, since some report increased tumorigenicity of the mixture with no modulation of the level of DNA adducts (Courter et al. 2008), while others found no impact on tumor formation and a lower level of adduct upon co-exposure (Marston et al. 2001).

Exposure to solar light, in particular the UV portion of its spectrum, is an additional parameter than can modulate the toxicity of PAH in skin and affect carcinogenicity (Dickel et al. 2016). UV can be absorbed by PAH and induce a photosensitized oxidative stress, as observed in several in vitro studies (Crallan et al. 2005; Mauthe et al. 1995; Soeur et al. 2017; Xia et al. 2015; Yu et al. 2006). UV may also induce degradation of PAH and lead to the formation of toxic photoproducts (Teranishi et al. 2010; Toyooka and Ibuki 2007). A third pathway involves the modulation of metabolism of PAH by UV, as suggested by the observed increase in the formation of DNA adducts in the skin of mice chronically co-exposed to UVA (320-400 nm) and B[a]P (Saladi et al. 2003). It has also been shown mostly in the HaCaT cell line that UVB $(280-320 \mathrm{~nm})$ radiation leads to the activation of the aryl hydrocarbon receptor (AhR). This resulted in a modest, yet significant increase in the induction of CYP450 metabolization enzyme (Fritsche et al. 2007; Rannug and Fritsche 2006). Using an indirect assay, favored formation of BPDE-DNA adducts was reported in UVB-irradiated HaCaT cells treated with B[a]P (Nair et al. 2009). In contrast, we recently reported 
that exposure to simulated sunlight (SSL) led to a decrease in CYP450 expression induced by B[a]P and strongly delayed the formation of DNA adducts quantified by a direct HPLC-mass spectrometry technique (von Koschembahr et al. 2018).

In spite of the works mentioned above, it appears that information is still missing on two key issues of the genotoxicity of PAH in skin, namely the mixture effect and the impact of their co-exposure with solar UV. The present project was designed to address these two points. We worked on human skin explants, which are relevant biological models of cutaneous tissue, topically exposed to organic extracts of PAH-containing materials from industrial origin. Additional experiments with pure $\mathrm{B}[\mathrm{a}] \mathrm{P}$ and synthetic mixtures were performed. In order to study the impact of UV radiation, we exposed skin to light emitted by a solar simulator either before or after topical application of the PAH mixtures. As biological endpoints, we quantified the expression of the genes coding for CYP450 1A1, 1A2 and 1B1, involved in the metabolism of PAH and efficiently expressed in skin (Costa et al. 2010; Swanson 2004; Villard et al. 2002), and monitored the level of DNA adducts to the most genotoxic $\mathrm{B}[\mathrm{a}] \mathrm{P}$ metabolite, its diol-epoxide derivative (BPDE) .

\section{Methods}

Preparation of skin explants. Human skin samples were obtained following breast surgery from healthy female donors (Centre Hospitalier Universitaire de Grenoble, Grenoble, France). All experiments were performed in accordance with relevant guidelines and regulations. In particular, work was performed in agreement with article L1245-2 of the French Public Health Code on the use of surgical wastes for research purposes. As stipulated, donors were informed and agreed to participate, and the samples were used anonymously. Declaration of collection and storage of human skin samples to the French authorities was validated in the CODECOH DC-2008-444 
document. All donors were between the ages of 17-58, and their skin phototype was either II or III, according to the Fitzpatrick classification scale. Upon receipt of the skin, an epidermal layer of $0.25 \mathrm{~mm}$ thickness was collected using a SOBER hand-held dermatome (Humeca, Enschede, Netherlands). Twelve mm biopsies were made with sterile punches (Help Medical, France). Samples were then placed in polystyrene inserts $(14 \mathrm{~mm}$ diameter, $1 \mu \mathrm{m}$ pore size filter, ThinCertTM, Greiner Bio-One, Austria) in 12 well plates (Greiner Bio-One, Austria). The explants were maintained at the liquid/air interface on $500 \mu \mathrm{L}$ of DMEM/F-12 medium (Thermo-Fisher) containing $10 \%$ Pen $/$ Strep at $37^{\circ} \mathrm{C}$ and $4 \%(w / v)$ bovine serum albumin in a humidified incubator containing $5 \% \mathrm{CO}_{2}$. In all experiments, the culture medium was changed every 24 hours.

Preparation of PAH mixtures. Mixtures of PAHs were prepared as described by Bourgart et al. (Bourgart et al. 2019). Briefly, mixtures were extracted from raw industrial materials and adjusted to the required concentrations of $\mathrm{B}[\mathrm{a}] \mathrm{P}$. Two coal tar pitch samples, CTP and $\mathrm{CTP}_{\mathrm{L}},(\mathrm{L}$ for "light") were used. The coal tar pitch was reduced to powder, suspended in $100 \mathrm{~mL}$ of $\mathrm{CH}_{2} \mathrm{Cl}_{2}$, and sonicated. An aliquot fraction of the liquid phase was evaporated to dryness and the resulting residue was dissolved and diluted in acetone (Sigma-Aldrich, St Quentin-Fallavier, France) in order to prepare solutions containing $0.2 \mathrm{mM}$ of $\mathrm{B}$ [a]P for the topical application of $1 \mathrm{nmol}$ in $5 \mu \mathrm{L}(\mathrm{CTP}-$

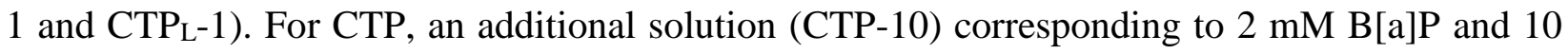
nmol in $5 \mu \mathrm{L}$ was also prepared. A similar protocol was applied to a petroleum coke sample (PC) in order to prepare a solution at $0.2 \mathrm{mM}$ in $\mathrm{B}$ [a]P in acetone (PC-1). The $\mathrm{PAH}$ composition of the mixtures was determined by HPLC with fluorescence detection, as previously described (Tarantini et al. 2011a). Synthetic mixtures of 12 PAHs in proportions found in the original materials were accurately reconstituted using PAH stock solutions for each of these solutions. They were diluted in acetone at either 0.2 or $2 \mathrm{mM} \mathrm{B}[\mathrm{a}] \mathrm{P}$, just like the raw extracts. These synthetic mixtures are 
referred to as CTP-S-10, CTP-S-1, CTP - -S-1 and PC-S-1. The twelve investigated PAH are among the priority EPA PAH and include: fluoranthene (Flua), pyrene (Pyr), benz[a]anthracene (B[a]A), chrysene $(\mathrm{Chr})$, benzo[e]pyrene $(\mathrm{B}[\mathrm{e}] \mathrm{P})$, benzo[b]fluoranthene $(\mathrm{B}[\mathrm{b}] \mathrm{F})$, benzo[k]fluoranthene $(\mathrm{B}[\mathrm{k}] \mathrm{F})$, benzo[a]pyrene $(\mathrm{B}[\mathrm{a}] \mathrm{P}), \quad$ dibenzo[a,h]anthracene $(\mathrm{dB}[\mathrm{ah}] \mathrm{A}), \quad$ benzo[g,h,i]perylene $(\mathrm{B}[\mathrm{ghi}] \mathrm{P})$, benzo[j]fluoranthene $(\mathrm{B}[\mathrm{j}] \mathrm{F})$, and indeno(1,2,3-c,d)pyrene (IP). All PAH were supplied by LGC Standards.

Treatment of skin with PAH mixtures. Different treatment protocols were applied to the skin explants. Several experiments involved exposure of skin explants to PAH only for increasing periods of time. For this purpose, $5 \mu \mathrm{L}$ of a solution in acetone of the chosen mixture of PAH was topically applied to the explant immediately following punch preparation. Fresh culture medium was added to each well and the samples were maintained in the incubator. Explants were collected after increasing periods of time. UV irradiations were performed using a LS1000 Solar Simulator (Solar Light Company, Glenside, PA), which emitted wavelengths in the 290-400 nm range. In all experiments, the dose of 2 minimal erythemal dose (MED), corresponding to $7.2 \mathrm{~J} / \mathrm{cm}^{2} \mathrm{UV}$ radiation, was used. Prior to irradiation, culture media was replaced by PBS. Irradiations were performed at room temperature at the liquid/air interface. Following irradiation, PBS was replaced with fresh culture medium. Irradiations were performed either 1 hour before (SSL/PAH protocol) or 24 hours after topical application of the PAH mixture of interest (PAH/SSL protocol). In both protocols, samples were collected 48 hours after the beginning of the PAH treatment. Additional experiments were performed with the SSL/PAH protocol with the explants collected only 24 hours after irradiation. For all treatment protocols, explants from three different donors, each with samples prepared in triplicates, were used. 
Viability assays. Quantification of cellular viability was based on the classical MTT assay performed both in skin explants and in primary cultures of keratinocytes prepared as previously reported (von Koschembahr et al. 2018). Skin explants were treated under the chosen experimental conditions. After $48 \mathrm{~h}$, the growing medium was removed and replaced with $500 \mu \mathrm{L}$ of fresh medium containing $0.5 \mathrm{mg} / \mathrm{ml}$ of MTT. The skin explants were then placed at $37^{\circ} \mathrm{C}$ in $5 \% \mathrm{CO}_{2}$. Viable explants slowly turned purple. After $2 \mathrm{~h}$, the explants were collected, rinsed in PBS and cut in pieces with a scalpel. DMSO $(500 \mu \mathrm{l})$ was added and the samples left for one hour at $37^{\circ} \mathrm{C}$. The assay with cultured keratinocytes was performed in 96-well plates as previously reported (von Koschembahr et al. 2018). For both series of experiments, viability was inferred from the absorption at $570 \mathrm{~nm}$ after subtraction of the measurement background.

Quantitative reverse transcription PCR. Gene expression analysis was performed, as previously described (von Koschembahr et al. 2018). Four phase I metabolism genes (CYPlAl, CYP1A2, CYP1B1, and EPHX1) were targeted. The skin was homogenized by use of a TissueRuptor (Qiagen). The resulting mixture was digested by proteinase $\mathrm{K}$, homogenized by a QiaShredder column, and RNA was isolated using a RNeasy Mini Kit combined with the RNasefree DNase system (Qiagen, Courtaboeuf, France). The amount of RNA in the samples was quantified using a ND1000 NanoDrop spectrophotometer. First strand cDNA was synthesized from $1.0 \mu \mathrm{g}$ of total RNA using the SuperScript VILO Synthesis Kit (Thermo-Fisher). Quantitative realtime polymerase chain reaction (RT-qPCR) was then performed using the human $\mathrm{RT}^{2} \mathrm{qPCR}$ primers and $\mathrm{RT}^{2} \mathrm{SYBR}$ Green qPCR Mastermix (Qiagen). Amplification was performed using the Bio-Rad CFX96 system (Bio-Rad, Marnes-la-Coquette, France). The Bio-Rad CFX96 system software was used to determine the cycle threshold (CT) values, and the comparative $\Delta \Delta \mathrm{CT}$ method was used to calculate the relative fold change of the 4 genes after normalization to GAPDH, 
RPS18, or $\beta$-Actin (Livak and Schmittgen 2001). Biological triplicates were processed individually for RNA isolation and analyzed in technical duplicates. Values were normalized to expression in control untreated samples.

Quantification of BPDE- $N^{2}$-dGuo. For DNA adduct quantification, DNA was extracted from the skin explants after homogenization in a TissueLyzer II using the ATL lysis buffer of a DNeasy Blood and Tissue Kit (Qiagen), combined with mechanical disruption using metal beads. Samples were then sequentially treated with proteinase $\mathrm{K}$ and RNaseA. After a second lysis step using AL buffer, ethanol was added and the samples were loaded onto DNeasy spin columns. After three wash steps, DNA was eluted off the column by adding $200 \mu \mathrm{L}$ of water. The collected samples were freeze-dried overnight and then solubilized in $50 \mu \mathrm{L}$ of water. DNA was hydrolyzed by a first incubation using phosphodiesterase II, DNase II, and nuclease P1 $\left(37^{\circ} \mathrm{C}, 2\right.$ hours). A second incubation step was then performed using phosphodiesterase I and alkaline phosphatase $\left(37^{\circ} \mathrm{C}, 2\right.$ hours). All enzymes used were purchased from Sigma-Aldrich. Samples were analyzed by HPLCtandem mass spectrometry. Separations were performed on reverse-phase HPLC column (150 x 2 mm ID, $3 \mu \mathrm{m}$ particle size, ODB, Interchim, Montluçon, France). The mobile phase was a gradient of acetonitrile (6 to $80 \%$ ) in $2 \mathrm{mM}$ ammonium formate (pH 6). Quantification of BPDE- $N^{2}$-dGuo was performed on a tandem mass spectrometer (SCIEX API 3000) with positive electrospray ionization. The detection was made in the multiple reaction monitoring mode using transitions $\mathrm{m} / \mathrm{z}$ $570 \rightarrow 257, \mathrm{~m} / \mathrm{z} 570 \rightarrow 454$ and $\mathrm{m} / \mathrm{z} 570 \rightarrow 282$ as previously described (Genies et al. 2013; Marie et al. 2008). Unmodified nucleosides were quantified with a UV detector and used to assess the amount of analyzed DNA. External calibration of the response of the two detectors was performed for each run of analyses, using repeated injections in order to control the stability of the sensitivity 
of the detection and of the retention times. Results were expressed in number of adducts per million normal bases.

Statistical analysis. Data were statistically analyzed in GraphPad PRISM using one-way ANOVA followed by Student-Newman-Keuls (SNK) for multiple comparisons. Statistical analyses were performed on pools of replicates originating from different donors.

\section{Results}

1. Experimental design

The relevance of the present work relied on three main aspects:

- The biological model. In order to be more realistic than 2D cell cultures, we used freshly prepared skin explants from breast surgery. In order to mimic cutaneous contamination, we applied PAH mixtures topically rather than in the culture medium. All donors were of phototype II or III.

- PAH mixtures relevant to occupational exposures. Organic extracts of coal tar pitch and petroleum coke were used (Table S1). Coal tar pitch is found in electrodes of silicon manufacturing, and in the bitumen used by roofers and asphalt workers. Two types of coal tar pitch, differing first in their overall PAH content, were used, with a ratio of 3.5 in the

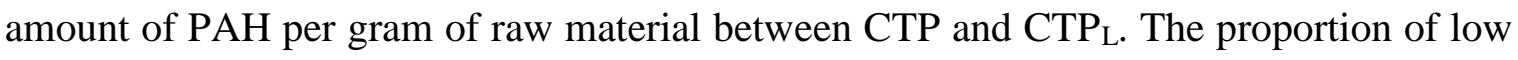
molecular weight PAH (4-ring compounds) was also different in the two products, with values of 46 and $76 \%$, respectively. We also included in our work an extract from petroleum coke (PC), a carbon-rich product used among other applications in the production of silicon carbide. This product was much poorer in PAH than coal tar pitches (70 and 30 times less 
than $\mathrm{CTP}$ and $\mathrm{CTP}_{\mathrm{L}}$, respectively), and almost devoid of 4-ring derivatives. In order to get additional insights in the effect of chemical complexity, we included in our study reconstituted synthetic PAH fractions of the later raw extracts and pure $\mathrm{B}[\mathrm{a}] \mathrm{P}$. The amount of mixtures used in our experiments are larger than actual exposures. Our work on chemical complexity of the mixtures was performed with amounts of $8.8 \mathrm{nmol} / \mathrm{cm}^{2} \mathrm{~B}[\mathrm{a}] \mathrm{P}$, namely only 10-times larger than the $0.1 \mathrm{nmol} / \mathrm{cm}^{2}$ values determined in aluminum factories workers (VanRooij et al. 1992). It should also be mentioned that our largest dose is lower than that used in some other works (Brinkmann et al. 2013; Moody et al. 1995; Sartorelli et al. 1999).

- The source of UV radiation. The vast majority of the published studies on the phototoxicity of PAH used either pure UVB or pure UVA. However, it is important to consider that human skin is never exposed to such pure sources of UV, and that concomitant and cooperative effects can take place between UVB and UVA. This is the reason why we performed all irradiations with a solar simulator emitting less than 5\% UVB, similar to solar irradiation that reaches the Earth's surface. The applied dose corresponded approximately to 50 min of exposure in summer in a mid-latitude European country with a UV index of 6 . Such conditions are highly relevant to occupational exposures.

It should be mentioned that a large fraction of the data were obtained with the same three donors as those used for the study of trans-epidermal migration of PAH and of their metabolites. The results of the latter work were recently published (Bourgart et al. 2019) and provide interesting insights on the present data. 


\section{Viability of skin explants}

The viability of the treated explants was investigated for the CTP and CTP-S mixtures, which are those applied to skin in the largest amount. Data were obtained by the robust MTT assay. A version of this technique was developed for skin explants. The same treatments as those used for gene expression and DNA damage quantification were applied to explants, together with a positive control consisting in topical application of $5 \mu \mathrm{L}$ of $10 \% \mathrm{w} / \mathrm{w}$ SDS in water (Table 1). We first confirmed the ability of our method at assessing cytotoxicity since the value for the positive control was 10-times lower than that of the untreated skin. SSL and CTP-S alone led to a $30 \%$ loss of viability. The irradiation before application of CTP-S led to a $70 \%$ viability while the reverse order of treatment in the PAH/SSL protocol decreased viability by a factor 2. Unfortunately, no information could be obtained in skin topically exposed to crude CTP extract because of the presence of interfering colorful compounds. To obtain information on this mixture, we performed MTT measurements on primary cultures of keratinocytes from 2 donors. Two concentrations of mixtures, corresponding to 0.01 and $0.1 \mu \mathrm{M}$ B[a]P were used. SSL (2 MED) induced 25\% loss of viability. Pure mixtures were less toxic, with a small concentration effect and a slightly better viability for CTP-S compared to CTP. Like in skin, exposure of SSL after addition of mixtures only slightly increased the effect of CTP-S and CTP. In contrast, the PAH/SSL protocol was much more cytotoxic for CTP-S in keratinocytes than in skin. The same strong loss of viability was observed in keratinocytes treated with CTP and then irradiated. It seems likely that the larger sensitivity of keratinocytes compared to skin is explained by the much more efficient contact between the PAHs and the cells in the former case. This would lead to larger intracellular concentration of PAH and a much more efficient photochemical enhancement of the effect of SSL. Altogether, it can be concluded that, in skin, the mixtures alone exhibit a moderate toxicity. SSL 
alone and the PAH/SSL protocol are somewhat more toxic but the loss of viability remains below $30 \%$. A stronger effect is observed for the PAH/SSL protocol with $50 \%$ viability.

\section{Expression of CYP450 genes upon exposure to complex mixtures}

In a first step, we investigated the extent of expression of three major genes coding for enzymes involved in the metabolism of PAH, the cytochrome $\mathrm{P} 450$ monooxygenases $1 A 1,1 A 2$, and $1 B 1$ in skin explants exposed to PAH for 48 hours (Fig. 1). The treatment time was selected based on our previous work that showed that it corresponded to the maximal expression of the 3 genes (von Koschembahr et al. 2018). RT-qPCR data showed that 10 nmol B[a]P significantly induced their overexpression with fold increases of 21 for $C Y P 1 A 1$ and 23 for $C Y P 1 A 2$. CYP1B1 was only overexpressed by a factor 3.5. The same order of increase in gene expression was observed in the skin samples exposed to the CTP and CTP-S PAH mixtures containing $10 \mathrm{nmol}$ B[a]P. The extent of overexpression of the CYP genes was roughly one order of magnitude larger with CTP-S than with pure $\mathrm{B}[\mathrm{a}] \mathrm{P}$. This difference was slightly lower for the CTP raw extract, which led to a 30 to $50 \%$ lower induction of CYP genes, compared to CTP-S. No significant modulation of the expression of the gene coding for epoxide hydrolase EPHX1 was observed (data not shown).

4. Formation of DNA adducts with pure B[a]P and mixtures

The level of BPDE- $N^{2}$-dGuo adducts was then measured in the same skin explants. We observed a drastic effect of the presence of compounds other than $\mathrm{B}[\mathrm{a}] \mathrm{P}$ in the mixture. While a level of $9.9 \pm$ 1.9 BPDE- $N^{2}$-dGuo per million bases was determined in skin exposed to $10 \mathrm{nmol}$ of pure $\mathrm{B}[\mathrm{a}] \mathrm{P}$, a 2-fold lower value, $5.4 \pm 0.8$ ( $\mathrm{p}<0.05$ ), was found in samples exposed to CTP-S-10. This ratio was more than 25 for skin exposed to crude CTP-10 where the level of BPDE- $N^{2}$-dGuo was 0.22 \pm 0.05 ( $\mathrm{p}<0.01)$. The same order in the level of content in DNA adducts $(\mathrm{B}[\mathrm{a}] \mathrm{P}>\mathrm{CTP}-\mathrm{S}>\mathrm{CTP})$ 
was observed between 24 and 72 hours, although at the value for CTP-S-10 was closer to that for B[a]P-10 samples at the 72 hour time-point (Fig. 2).

5. Effect of the nature of the mixture on DNA adducts formation.

We then investigated the formation of BPDE- $N^{2}$-dGuo in skin samples from three other donors exposed to pure $\mathrm{B}[\mathrm{a}] \mathrm{P}$ and to the three different $\mathrm{PAH}$ mixtures. The concentrations in $\mathrm{B}[\mathrm{a}] \mathrm{P}$ in $\mathrm{CTP}_{\mathrm{L}}$ and PC are very low. Adding $10 \mathrm{nmol}$ of $\mathrm{B}[\mathrm{a}] \mathrm{P}$ with these solutions would thus necessitate the preparation of highly concentrated solutions above saturation. Therefore, we limited the applied amount of $\mathrm{B}[\mathrm{a}] \mathrm{P}$ to $1 \mathrm{nmol}$. At this dose, the lower level of adducts produced by pure $\mathrm{B}$ [a]P with comparison with the synthetic mixtures CTP-S-1, CTPL-S-1, and PC-S-1 did not reach statistical significance (Fig. 3). In contrast, the inhibition of the formation of BPDE- $N^{2}$-dGuo was larger for the raw extracts, in particular $\mathrm{CTP}_{\mathrm{L}}-1$ and PC-1. No statistically significant difference was observed between CTP-S-1 and CTP-1, but a one order of magnitude lower level of adduct was observed in the crude extracts compared to the synthetic mixtures for $\mathrm{CTP}_{\mathrm{L}}-1$ and $\mathrm{PC}-1$. It may be added that, unexpectedly, the level of DNA adducts of skin exposed to CTP-1 was more than twice that found in the DNA of explants exposed to a 10-times larger dose (CPT-10, Fig. 2).

6. Impact of simulated sunlight on PAH-mediated gene induction

Investigation of the effect of solar UV was performed with explants from the same donors as those used in part 3 and 4 . In terms of gene expression (Table 2), exposure to SSL alone only slightly increased the expression of CYP genes. A 2-fold increase was also mediated by the exposure to SSL in samples exposed to $\mathrm{B}[\mathrm{a}] \mathrm{P}$ only. However, these differences did not reach statistical significance. A significant inhibitory effect of exposure to SSL 1 hour before incubation with PAH was observed on the modulation of gene expression in skin samples exposed to CTP-S-10 and CTP-10, with the exception of CYP1B1 with CTP-10. A similar statistically significant inhibitory 
effect was observed for the 3 genes when explants were incubated with CTP-S-10 24 hours before exposure to SSL. A statistically significant lower induction of $C Y P 1 A 2$ was also observed with CTP-10. As a general trend, the inhibitory effects of SSL on gene induction were more pronounced with crude extracts rather than synthetic mixtures.

7. Formation of DNA adducts upon co-exposure to SSL and PAH mixtures

We then quantified the level of BPDE- $N^{2}$-dGuo in the samples of skin explants exposed to SSL and to PAH mixtures for 48 hours (Table 3). A strong and significant inhibitory effect was observed for the synthetic mixture CTP-S-10 in both the SSL/PAH and PAH/SSL protocols. The decrease induced by the exposure to SSL compared to the PAH treatment only was 3.8 and 2.1, respectively. A lower and not statistically significant effect was observed for pure B[a]P with SSL-induced decrease of 1.4 under both protocols. No clear trend was observed for the crude mixture because the HPLC-MS/MS signal was at the limit of quantification and the error on the measure was too high to draw clear conclusions (data not shown). In order to complete these data, we repeated the SSL/PAH protocol with collection of the explants after 24 hours instead of 48 hours of treatment. Under these conditions, a statistically lower level of DNA adducts was observed in irradiated samples for both $\mathrm{B}[\mathrm{a}] \mathrm{P}-10$ and $\mathrm{CTP}-\mathrm{S}-10$. The respective inhibitory effect of SSL on the formation of BPDE- $N^{2}$-dGuo was 6.5 and 2.2 (Table 3).

\section{Discussion}

In contrast to the general population where cutaneous contamination by PAH is minor, this exposure route is a key issue in occupational health. Indeed, workers in specific industries can be exposed to high levels of this class of toxic chemicals, depending on their tasks (Forster et al. 2008). 
Risk assessment is therefore critical, but represents a major challenge for two reasons. The first is the large diversity of chemical complexity of the mixtures that workers are exposed to. PAH are found in different proportions and in different matrices, depending on the products which are manufactured or used. A second issue for skin toxicity is the confounding role of exposure to sunlight, either during working hours or after, which may induce PAH-mediated processes and modulate the skin's biological response to PAH.

Effect of the chemical complexity was presently investigated with crude organic extracts from coal tar pitch (CTP) or the corresponding synthetically reconstituted fractions containing 12 major PAH (CTP-S). The two solutions were topically applied for 48 hours to skin explants in amounts containing $10 \mathrm{nmol} \mathrm{B}[\mathrm{a}] \mathrm{P}$. Induction of $C Y P 1 A 1,1 A 2$, and to a lesser extent $1 \mathrm{~B} 1$, was larger in skin exposed to CTP-S-10 and CTP-10 compared to $10 \mathrm{nmol}$ pure B[a]P. Interestingly, expression of $C Y P 1 A 1$ and $1 A 2$ was roughly 10 -times higher with $\mathrm{CTP}-\mathrm{S}-10$ than $\mathrm{B}[\mathrm{a}] \mathrm{P}-10$, namely in a ratio very close to the ratio between the overall applied amount of $\mathrm{PAH}$. Indeed, the total PAH concentration of CTP-S is $24 \mathrm{mM}$ compared to $2 \mathrm{mM} \mathrm{B}$ [a]P. On the same line, the increase in expression induced by $10 \mathrm{nmol} \mathrm{B}[\mathrm{a}] \mathrm{P}$ is roughly one order of magnitude lower than the induction we observed in similar experiments involving topical application of $100 \mathrm{nmol} \mathrm{B}$ [a]P (von Koschembahr et al. 2018). These observations strongly suggest that, under our experimental conditions, the amount of applied mixture containing only PAH was not large enough to saturate the response in gene expression, unlike what has sometimes been proposed (Jacques et al. 2010; $\mathrm{Ng}$ et al. 1992). Yet, we observed a 2-fold lower induction of CYP in explants exposed to the crude CTP extract than to the synthetic mixture. The observed difference strongly suggests a mild, but significant inhibitory effect of chemicals other than PAH present in the raw mixture on CYP gene induction. 
In contrast to gene expression, the level of adducts between DNA and the most deleterious $\mathrm{B}[\mathrm{a}] \mathrm{P}$ metabolite, BPDE, strongly decreased with increasing chemical complexity. Although all skin explants were exposed to $10 \mathrm{nmol} \mathrm{B}[\mathrm{a}] \mathrm{P}$, the amount of BPDE- $N^{2}$-dGuo was 2.5 and 22 times lower in skin exposed to CPT-S-10 and CPT-10, respectively, than to pure B[a]P after 48 hours exposure. This extent of DNA damage formation inversely follows the order of chemical complexity since CTP-S contains only $12 \mathrm{PAH}$, while raw CTP also contains other PAH as well as chemicals of different types. The low level of DNA adducts upon complex mixture exposure was also observed in skin of patients treated with coal tar ointments (CTO). Values ranging between 0.3 and 0.01 adducts per $10^{6}$ bases were found following exposure to CTO containing 60 $\mathrm{pmol} / \mathrm{cm}^{2} \mathrm{~B}[\mathrm{a}] \mathrm{P}$ (Godschalk et al. 1998). Exposure of healthy volunteers to CTO resulted in 10times fewer $\mathrm{B}[\mathrm{a}] \mathrm{P}$ content, leading to a frequency of $\mathrm{PAH}$ adducts of 0.2 per $10^{6}$ bases (Roelofzen et al. 2012). Interestingly, the observation of a decreased formation of adducts with increasing mixture complexity was also made in our skin explants for tetraol, the final product of BPDE, and all other PAH metabolites investigated (Bourgart et al. 2019). These results show that decreased formation of DNA adducts is mostly explained by reduced production of metabolites and not by modulation of other cellular pathways. When other mixtures $\left(\mathrm{CTP}, \mathrm{CTP}_{\mathrm{L}}\right.$, and $\left.\mathrm{CP}\right)$ were applied in amount containing $1 \mathrm{nmol} \mathrm{B}[\mathrm{a}] \mathrm{P}$, the formation of BPDE adducts also followed a trend opposite to the chemical complexity. The highest level of BPDE- $N^{2}$-dGuo was observed in explants exposed to CTP-1 where PAH represent $2.8 \%$ of the overall crude starting product. A 7 - and 3-fold lower value of DNA adducts was observed for $\mathrm{CTP}_{\mathrm{L}}$ and $\mathrm{CP}$, respectively, which both contain lower PAH proportion ( 0.8 and $0.03 \% \mathrm{PAH}$, respectively) than CTP. The impact of chemical complexity is even more obvious when the proportion of only $\mathrm{B}[\mathrm{a}] \mathrm{P}$ is considered, since the corresponding values are $0.23,0.04$, and $0.01 \%$ for $\mathrm{CTP}, \mathrm{CTP}_{\mathrm{L}}$, and $\mathrm{PC}$, respectively. Another interesting observation was made when comparing the formation of DNA adducts in skin exposed to either 
$\mathrm{B}[\mathrm{a}] \mathrm{P}-10$ or CTP-S-10. The values were lower for CTP-S-10 than B[a]P-10 at 48 hours and even more at 24 hours. However, the values at 72 hours were closer. This trend reflects the production of metabolites in skin exposed to CTP-S, which is low during the first 48 hours but increases by a factor 5 to 10 depending on the PAH between 48 and 72 hours (Bourgart et al. 2019). It is possible that the slow biotransformation in the first period of time reduces the chemical complexity enough to allow, after 48 hours, a more efficient metabolization of PAH. This suggest the existence of a threshold under which chemical complexity less efficiently decreases metabolism.

The decrease in metabolism of $\mathrm{PAH}$, and in particular of $\mathrm{B}[\mathrm{a}] \mathrm{P}$, with increasing chemical complexity of the exposure cannot be explained by a decrease in CYP450 gene expression, at least when results obtained with pure $\mathrm{B}[\mathrm{a}] \mathrm{P}$ are compared with synthetic or crude extracts. Indeed, as discussed above, induction of CYP genes is much higher with the mixtures. Lower expression of genes with raw extracts than synthetic mixtures could partly explain the DNA adducts results. However, the difference in gene expression observed between CTP-S and CTP is only a factor of 2 while the corresponding ratio for the level of adducts is approximatively 10 for $\mathrm{CTP}-10, \mathrm{CTP}_{\mathrm{L}^{-}}$ 1, and PC-1. An alternative explanation to our observation of a lower level of B[a]P adducts in the explants exposed to the more complex mixtures could be a slower migration of parent PAHs in the skin, thereby decreasing the amount of substrate for metabolism enzymes. Measurements performed in our samples showed that although the amount of PAH remaining at the surface of the explants was higher with raw extracts than with synthetic mixtures, the content within the skin was similar in both cases (Bourgart et al. 2019).

The link between inhibition of metabolism and increased chemical complexity is rather in agreement with another hypothesis, namely the occurrence of competition and inhibition in the biotransformation enzymatic reactions (Dankovic et al. 1989; Pushparajah and Ioannides 2018; 
Shimada et al. 2007; Shimada et al. 2008). Exposure to mixtures, which may be as simple as binary mixtures, exhibit different effects, depending on the cell type. In cultured hepatocytes and liver slices, PAH-rich mixtures were found to also exhibit synergistic effects on the metabolism and genotoxicity of B[a]P (Sevastyanova et al. 2007; Staal et al. 2008; Staal et al. 2007; Tarantini et al. 2011a; Tarantini et al. 2011b). In contrast, inhibition of the latter processes was always observed for cells with low metabolism capacities, like pulmonary cells (Binkova and Sram 2004; Genies et al. 2016; Sevastyanova et al. 2007). By analogy, our present observations could be explained by the fact that the amount of CYP450 proteins expressed in skin is low, and that competition between components of the mixtures exhibit a drastic effect. The observation that, for the less complex mixture CTP, the level of BDPE-DNA adducts increases when the applied amount decreases from 10 to $1 \mathrm{nmol}$ can be explained by a lower competition between PAH and other chemicals. This unexpected dilution effect is not observed with the other mixtures, where PAH represents a lesser fraction and which exhibit a larger complexity. The bulk of these results points again to a threshold in the inhibition of metabolism by mixtures that further complicates risk assessment.

Additional explanations could be found in the expression of genes and proteins. A major impact of the mixtures on EPHX and phase 2 enzymes, such as GST, is unlikely. Indeed, we have shown in a previous work that expression of the corresponding genes was not affected by exposure to 100 nmol B[a]P (von Koschembahr et al. 2018). The impact of exposure to complex mixtures on PAH metabolism could also result from modulation of epigenetics factors, as suggested by a growing number of studies (Hu and Yu 2019). Therefore, more research will be needed, since studies report either hyper- (He et al. 2015) or hypomethylation of DNA (Liu et al. 2019). A more likely hypothesis is the involvement of aldo-keto reductases (AKR). These enzymes can convert B[a]P dihydrodiol in the corresponding catechol, thereby preventing its subsequent epoxidation by 
CYP450 into BPDE. This role of AKR has been well documented for lung cells (Abedin et al. 2012; Palackal et al. 2002). We proposed that the larger expression of AKRC1, together with that of the multi resistance protein 4, in A549 lung cells compared to HepG2 hepatocytes explained why the dose-course formation of DNA adducts was proportional to the concentration in the latter cells, but reach saturation at $200 \mathrm{nM}$ in the former (Genies et al. 2013).

After chemical complexity, we investigated the impact of exposure to simulated sunlight on the metabolism and genotoxicity of PAH mixtures. In agreement with reports made in HaCaT cells (Fritsche et al. 2007; Rannug and Fritsche 2006), as well as in primary culture of human keratinocytes and human skin explants (von Koschembahr et al. 2018), we observed that exposure to SSL alone slightly activated the expression of $C Y P 450$ genes by a factor of 2 . We also observed that exposure of explants to SSL before or after treatment with $10 \mathrm{nmol} \mathrm{B}[\mathrm{a}] \mathrm{P}$ exhibited the same effect, although without reaching statistical significance. The latter observation contrasts with our recent results obtained following exposure to $100 \mathrm{nmol} \mathrm{B}$ [a]P in skin explants where a 2- to 3-fold decrease in gene expression was observed (von Koschembahr et al. 2018). Comparison of these two studies suggests a possible dose-effect. A significant decrease in gene expression was observed upon co-exposure of skin explants to sunlight and either CTP-S-10 or CTP-10 mixtures. This trend was particularly significant with the crude extracts and when SSL was applied before treatment with PAH. These results show, as we reported in our previous study involving pure B[a]P applied to skin or primary keratinocytes (von Koschembahr et al. 2018), that the mild stimulation of CYP450 genes expression by SSL alone has no direct consequences when skin is co-exposed to PAH. This conclusion reinforces our previous hypothesis that endogenous photoproducts responsible for the induction of AhR-dependent pathways either weakly bind to this factor or are 
present in very low concentration and therefore cannot compete with exogenous ligands like PAH (Youssef et al. 2018).

This SSL-mediated inhibition of metabolism is, as expected, reflected in the formation of BPDEDNA adducts in explants exposed for 48 hours to pure B[a]P (although without reaching statistical significance), CTP-S, and CTP. A stronger effect on BPDE-DNA adducts has been observed in our previous work with larger amount of pure $\mathrm{B}[\mathrm{a}] \mathrm{P}$ (von Koschembahr et al. 2018). In order to determine whether different formation kinetics could be induced by a lower dose, we repeated the previous analyses at 24 hours instead of 48 hours. At this shorter time point, the impact of the exposure to SSL before exposure to $\mathrm{B}[\mathrm{a}] \mathrm{P}$ and $\mathrm{PAH}$ mixture was much stronger than at 48 hours, thereby providing stronger support for an inhibitory effect of UV on metabolism and genotoxicity of PAH in mixtures. This observed time-dependence is yet reminiscent of results obtained with 100 nmol B[a]P (von Koschembahr et al. 2018), suggesting that the formation of adducts is not completely inhibited with synthetic mixtures, but seems rather to be delayed. An alternative explanation to the decreased level of DNA adducts upon co-exposure to PAH and SSL could have been as a result of photodegradation of the PAH at the surface of the explants (Yu et al. 2006). This seems very unlikely because the strongest effect of inhibition of CYP450 gene expression and DNA damage formation was observed when irradiations were performed before application of PAH. In addition, we measured the composition of CTP and CTP-S irradiated in the dry state on a glass plate and could not find any difference with the initial mixtures (data not shown). An additional explanation could be the increased penetration of parent PAH observed in irradiated skin (Bourgart et al. 2019; Hopf et al. 2018). Interestingly, there is one report of a stimulation of the expression of the gene coding for AKR1C in keratinocytes exposed to UVB (Marin et al. 2009). 
This observation could make the link between our observation of the effects of chemical complexity of the mixtures and of SSL.

\section{Conclusion}

Our present data emphasize the role of two important factors in the genotoxicity of PAH in skin upon occupational exposure: the composition of the contaminating mixture and the modulation by the UV portion of sunlight. We provide clear evidence that induction of metabolism is not hampered by the mixture effect. However, although genes are expressed, individual PAHs are less efficiently metabolized as the mixture complexity increases, likely as the result of competition for enzymatic processes. This is well-illustrated in the present work for $\mathrm{B}[\mathrm{a}] \mathrm{P}$ through the quantification of its DNA adducts. The strong mixture effects observed, in addition to a threshold evidenced by unexpected dilution effects, reinforce the growing need for risk assessment tools which do not depend on additivity principle, unlike Toxic Equivalency Factors. The same conclusion can be made regarding the modulation effect of solar UV radiation, which decreases the metabolism capacities of skin and delays the formation of DNA adducts. In terms of occupational safety, these two important results may be positive observations suggesting a reduced immediate toxicity. Conversely, these results also mean that PAH are less rapidly metabolized and eliminated, thereby expanding the duration of the internal exposure. It should be stressed that our work only involved a limited number of donors, all of them being women. It would be interesting to investigate how our observations are modulated within a population with different polymorphisms in metabolism genes. Some of them are associated with increased cancer risk upon exposure to PAH and other xenobiotics (Gajecka et al. 2005; Olshan et al. 2000). In addition, 
investigation of the gender effect is important since it is known most of the jobs associated with high PAH exposure are mostly made by men (Scarselli et al. 2018).

\section{Conflict of Interest}

The authors state no conflict of interest.

\section{Acknowledgements}

The authors wish to thank the team of the "Service de Chirurgie Plastique et Maxillo-faciale CHU Grenoble Alpes" for their help in skin sample collection. This work was supported by grants \#ENV201411 and \#ENV201604 from INSERM and Plan Cancer.

\section{References}

Abedin Z, Sen S, Field J (2012) Aldo-keto reductases protect lung adenocarcinoma cells from the acute toxicity of B[a]P-7,8-trans-dihydrodiol. Chem Res Toxicol 25:113-121

Baird WM, Hooven LA, Mahadevan B (2005) Carcinogenic polycyclic aromatic hydrocarbonDNA adduct and mechanism of action. Environ Mol Mutagen 45:106-114

Bickers DR, Mukhtar H, Dutta-Choudhury T, Marcelo CL, Voorhees JJ (1984) Aryl Hydrocarbon Hydroxylase, Epoxide Hydrolase, and Benzo[a]pyrene Metabolism in Human Epidermis: Comparative Studies in Normal Subjects and Patients with Psoriasis. J Invest Dermatol $83: 51-56$

Binkova B, Sram RJ (2004) The genotoxic effect of carcinogenic PAHs, their artificial and environmental mixtures (EOM) on human diploid lung fibroblasts. Mutat Res 547:109-121

Boffetta P, Jourenkova N, Gustavsson P (1997) Cancer risk from occupational and environmental exposure to polycyclic aromatic hydrocarbons. Cancer Causes Control 8:444-72

Bourgart E, Persoons R, Marques M, et al. (2019) Influence of exposure dose, complex mixture and ultraviolet radiation on skin absorption and bioactivation of polycyclic aromatic hydrocarbons ex vivo. Arch Toxicol 93:2165-2184 
Brinkmann J, Stolpmann K, Trappe S, et al. (2013) Metabolically Competent Human Skin Models: Activation and Genotoxicity of Benzo a pyrene. Toxicol Sci 131:351-359

Costa C, Catania S, De Pasquale R, Stancanelli R, Scribano GM, Melchini A (2010) Exposure of human skin to benzo[a]pyrene: role of CYP1A1 and aryl hydrocarbon receptor in oxidative stress generation. Toxicology 271:83-6

Courter LA, Luch A, Musafia-Jeknic T, et al. (2008) The influence of diesel exhaust on polycyclic aromatic hydrocarbon-induced DNA damage, gene expression, and tumor initiation in Sencar mice in vivo. Cancer Lett 265:135-47

Crallan RA, Ingham E, Routledge MN (2005) Wavelength dependent responses of primary human keratinocytes to combined treatment with benzo[a]pyrene and UV light. Mutagenesis 20:305-310

Dankovic DA, Wright CW, Zangar RC, Springer DL (1989) Complex mixture effects on the dermal absorption of benzo a pyrene and other polycyclic aromatic-hydrocarbons from mouse skin. J Appl Toxicol 9:239-244

Darwiche N, Ryscavage A, Perez-Lorenzo R, et al. (2007) Expression profile of skin papillomas with high cancer risk displays a unique genetic signature that clusters with squamous cell carcinomas and predicts risk for malignant conversion. Oncogene 26:6885-95

Deschamps F, Barouh M, Deslee G, Prevost A, Munck J-N (2006) Estimates of work-related cancers in workers exposed to carcinogens. Occup Med 56:204-209

Dickel H, Blome O, Dickel B, Bruckner T, Stockfleth E, Soemantri SP (2016) Occupational syncarcinogenesis in the skin - combined effects of two carcinogens from the German occupational disease list. J Dtsch Dermatol Ges 14:1284-1296

Forster K, Preuss R, Rossbach B, Bruning T, Angerer J, Simon P (2008) 3-Hydroxybenzo[a]pyrene in the urine of workers with occupational exposure to polycyclic aromatic hydrocarbons in different industries. Occup Environ Med 65:224-9

Fritsche E, Schafer C, Calles C, et al. (2007) Lightening up the UV response by identification of the arylhydrocarbon receptor as a cytoplasmatic target for ultraviolet B radiation. Proc Natl Acad Sci USA 104:8851-6

Fustinoni S, Campo L, Cirla PE, et al. (2010) Dermal exposure to polycyclic aromatic hydrocarbons in asphalt workers. Occup Environ Med 67:456-63

Gajecka M, Rydzanicz M, Jaskula-Sztul R, Kujawski M, Szyfter W, Szyfter K (2005) CYP1A1, CYP2D6, CYP2E1, NAT2, GSTM1 and GSTT1 polymorphisms or their combinations are associated with the increased risk of the laryngeal squamous cell carcinoma. Mutat Res 574:112-123

Genies C, Jullien A, Lefebvre E, Revol M, Maitre A, Douki T (2016) Inhibition of the formation of benzo[a]pyrene adducts to DNA in A549 lung cells exposed to mixtures of polycyclic aromatic hydrocarbons. Toxicol In Vitro 35:1-10

Genies C, Maitre A, Lefebvre E, Jullien A, Chopard-Lallier M, Douki T (2013) The extreme variety of genotoxic response to benzo[a]pyrene in three different human cell lines from three different organs. PLoS One 8:e78356 
Godschalk RWL, Ostertag JU, Moonen EJC, Neumann HAM, Kleinjans JCS, van Schooten FJ (1998) Aromatic DNA adducts in human white blood cells and skin after dermal application of coal tar. Cancer Epidemiology Biomarkers \& Prevention 7:767-773

He ZN, Duan HW, Zhang BA, et al. (2015) CpG site-specific RASSF1a hypermethylation is associated with occupational PAH exposure and genomic instability. Toxicology Research 4:848-857

Herbert R, Marcus M, Wolff MS, et al. (1990) Detection of adducts of deoxyribonucleic acid in white blood cells of roofers by 32P-postlabeling. Relationship of adduct levels to measures of exposure to polycyclic aromatic hydrocarbons. Scand J Work Environ Health 16:135-43

Hopf NB, Spring P, Hirt-Burri N, et al. (2018) Polycyclic aromatic hydrocarbons (PAHs) skin permeation rates change with simultaneous exposures to solar ultraviolet radiation (UV-S). Toxicol Lett 287:122-130

Hu JJ, Yu YX (2019) Epigenetic response profiles into environmental epigenotoxicant screening and health risk assessment: A critical review. Chemosphere 226:259-272

Hughes NC, Phillips DH (1993) 32P-postlabelling analysis of the covalent binding of benzo[ghi]perylene to DNA in vivo and in vitro. Carcinogenesis 14:127-33

IARC (2010) Some non-heterocyclic polycyclic aromatic hydrocarbons and some related exposures, vol 92. IARC, Lyon

Jacques C, Perdu E, Duplan H, et al. (2010) Disposition and biotransformation of 14CBenzo(a)pyrene in a pig ear skin model: ex vivo and in vitro approaches. Toxicol Lett 199:22-33

Jarvis IWH, Bergvall C, Bottai M, Westerholm R, Stenius U, Dreij K (2013) Persistent activation of DNA damage signaling in response to complex mixtures of PAHs in air particulate matter. Toxicol Appl Pharmacol 266:408-418

Jarvis IWH, Dreij K, Mattsson A, Jernstrom B, Stenius U (2014) Interactions between polycyclic aromatic hydrocarbons in complex mixtures and implications for cancer risk assessment. Toxicology 321:27-39

Jeffrey AM, Weinstein IB, Jennette KW, et al. (1977) Structures of benzo(a)pyrene--nucleic acid adducts formed in human and bovine bronchial explants. Nature 269:348-50

Liu YL, Li XJ, Zhang B, et al. (2019) CYP1A1 methylation mediates the effect of smoking and occupational polycyclic aromatic hydrocarbons co-exposure on oxidative DNA damage among Chinese coke-oven workers. Environmental Health 18

Livak KJ, Schmittgen TD (2001) Analysis of relative gene expression data using real-time quantitative PCR and the 2(-Delta Delta C(T)) Method. Methods 25:402-8

Marie C, Maître A, Douki T, et al. (2008) Influence of the metabolic properties of human cells on the kinetic of formation of the major benzo[a]pyrene DNA adducts. J Appl Toxicol 28:579590

Marin YE, Seiberg M, Lin CB (2009) Aldo-keto reductase 1C subfamily genes in skin are UVinducible: possible role in keratinocytes survival. Exp Dermatol 18:611-8 
Marston CP, Pereira C, Ferguson J, et al. (2001) Effect of a complex environmental mixture from coal tar containing polycyclic aromatic hydrocarbons (PAH) on the tumor initiation, PAHDNA binding and metabolic activation of carcinogenic PAH in mouse epidermis. Carcinogenesis 22:1077-86

Mauthe RJ, Cook VM, Coffing SL, Baird WM (1995) Exposure of mammalian cell cultures to benzo[a]pyrene and light results in oxidative DNA damage as measured by 8hydroxydeoxyguanosine formation. Carcinogenesis 16:133-7

Moody RP, Nadeau B, Chu I (1995) In-Vivo and in-Vitro Dermal Absorption of Benzo[a]Pyrene in Rat, Guinea-Pig, Human and Tissue-Cultured Skin. J Dermatol Sci 9:48-58

Nair S, Kekatpure VD, Judson BL, et al. (2009) UVR exposure sensitizes keratinocytes to DNA adduct formation. Cancer Prev Res 2:895-902

Ng KM, Chu I, Bronaugh RL, Franklin CA, Somers DA (1992) Percutaneous absorption and metabolism of pyrene, benzo[a]pyrene, and di(2-ethylhexyl) phthalate: comparison of in vitro and in vivo results in the hairless guinea pig. Toxicol Appl Pharmacol 115:216-223

Nisbet IC, LaGoy PK (1992) Toxic equivalency factors (TEFs) for polycyclic aromatic hydrocarbons (PAHs). Regul Toxicol Pharmacol 16:290-300

Olshan AF, Weissler MC, Watson MA, Bell DA (2000) GSTM1, GSTT1, GSTP1, CYP1A1, and NAT1 polymorphisms, tobacco use, and the risk of head and neck cancer. Cancer Epidemiology Biomarkers \& Prevention 9:185-191

Palackal NT, Lee SH, Harvey RG, Blair IA, Penning TM (2002) Activation of polycyclic aromatic hydrocarbon trans-dihydrodiol proximate carcinogens by human aldo-keto reductase (AKR1C) enzymes and their functional overexpression in human lung carcinoma (A549) cells. J Biol Chem 277:24799-24808

Park JH, Mangal D, Frey AJ, Harvey RG, Blair IA, Penning TM (2009) Aryl hydrocarbon receptor facilitates DNA strand breaks and 8-oxo-2'-deoxyguanosine formation by the aldo-keto reductase product benzo[a]pyrene-7,8-dione. J Biol Chem 284:29725-29734

Peltonen K, Dipple A (1995) Polycyclic aromatic hydrocarbons: chemistry of DNA adduct formation. J Occup Environ Med 37:52-58

Pukkala E, Martinsen JI, Weiderpass E, et al. (2014) Cancer incidence among firefighters: 45 years of follow-up in five Nordic countries. Occup Environ Med 71:398-404

Pushparajah DS, Ioannides C (2018) Antagonistic and synergistic interactions during the binding of binary mixtures of polycyclic aromatic hydrocarbons to the aryl hydrocarbon receptor. Toxicol In Vitro 50:54-61

Rannug A, Fritsche E (2006) The aryl hydrocarbon receptor and light. Biol Chem 387:1149-1157

Rice JE, Hosted TJ, Jr., Lavoie EJ (1984) Fluoranthene and pyrene enhance benzo[a]pyrene--DNA adduct formation in vivo in mouse skin. Cancer Lett 24:327-33

Roelofzen JHJ, Aben KKH, Van Der Valk PGM, Van Houtum JLM, Van De Kerkhof PCM, Kiemeney L (2007) Coal tar in dermatology. Journal of Dermatological Treatment 18:329334 
Roelofzen JHJ, van der Valk PGM, Godschalk R, et al. (2012) DNA adducts in skin biopsies and 1-hydroxypyrene in urine of psoriasis patients and healthy volunteers following treatment with coal tar. Toxicol Lett 213:39-44

Safe S (1990) Polychlorinated-biphenyls (PCBS), dibenzo-para-dioxins (PCDDS), dibenzofurans (PCDFS), and related-compounds - environmental and mechanistic considerations which support the development of toxic equivalency factors (TEFS). Crit Rev Toxicol 21:51-88

Saladi R, Austin L, Gao D, et al. (2003) The combination of benzo[a]pyrene and ultraviolet A causes an in vivo time-related accumulation of DNA damage in mouse skin. Photochem Photobiol 77:413-9

Sartorelli P, Cenni A, Matteucci G, Montomoli L, Novelli MT, Palmi S (1999) Dermal exposure assessment of polycyclic aromatic hydrocarbons: in vitro percutaneous penetration from lubricating oil. Int Arch Occ Env Hea 72:528-532

Scarselli A, Corfiati M, Di Marzio D, Marinaccio A, Iavicoli S (2018) Gender differences in occupational exposure to carcinogens among Italian workers. BMC Public Health 18:413

Sevastyanova O, Binkova B, Topinka J, et al. (2007) In vitro genotoxicity of PAH mixtures and organic extract from urban air particles: Part II: Human cell lines. Mutat Res 620:123-134

Shimada T, Fujii-Kuriyama Y (2004) Metabolic activation of polycyclic aromatic hydrocarbons to carcinogens by cytochromes P450 1A1 and 1B1. Cancer Sci 95:1-6

Shimada T, Murayama N, Okada K, Funae Y, Yamazaki H, Guengerich FP (2007) Different mechanisms for inhibition of human cytochromes P450 1A1, 1A2, and 1B1 by polycyclic aromatic inhibitors. Chem Res Toxicol 20:489-96

Shimada T, Murayama N, Tanaka K, et al. (2008) Interaction of polycyclic aromatic hydrocarbons with human cytochrome P450 1B1 in inhibiting catalytic activity. Chem Res Toxicol 21:2313-2323

Siddens LK, Larkin A, Krueger SK, et al. (2012) Polycyclic aromatic hydrocarbons as skin carcinogens: Comparison of benzo[a]pyrene, dibenzo[def,p]chrysene and three environmental mixtures in the FVB/N mouse. Toxicol Appl Pharmacol 264:377-386

Smolarek TA, Baird WM, Fisher EP, DiGiovanni J (1987) Benzo(e)pyrene-induced alterations in the binding of benzo(a)pyrene and 7,12-dimethylbenz(a)anthracene to DNA in Sencar mouse epidermis. Cancer Res 47:3701-6

Soeur J, Belaidi JP, Chollet C, et al. (2017) Photo-pollution stress in skin: Traces of pollutants (PAH and particulate matter) impair redox homeostasis in keratinocytes exposed to UVA1. J Dermatol Sci 86:162-169

Staal YCM, Pushparajah DS, Van Herwijnen MHM, et al. (2008) Interactions between polycyclic aromatic hydrocarbons in binary mixtures: Effects on gene expression and DNA adduct formation in precision-cut rat liver slices. Mutagenesis 23:491-499

Staal YCM, Van Herwijnen MHM, Pushparajah DS, et al. (2007) Modulation of gene expression and DNA-adduct formation in precision-cut liver slices exposed to polycyclic aromatic hydrocarbons of different carcinogenic potency. Mutagenesis 22:55-62

Swanson HI (2004) Cytochrome P450 expression in human keratinocytes: an aryl hydrocarbon receptor perspective. Chem Biol Interact 149:69-79 
Tarantini A, Douki T, Personnaz MB, Besombes JL, Jafrezzo JL, Maitre A (2011a) Effect of the chemical composition of organic extracts from environmental and industrial atmospheric samples on the genotoxicity of polycyclic aromatic hydrocarbons mixtures. Toxicol Environ Chem 93:941-954

Tarantini A, Maitre A, Lefebvre E, et al. (2009) Relative contribution of DNA strand breaks and DNA adducts to the genotoxicity of benzo[a]pyrene as a pure compound and in complex mixtures. Mutat Res 671:67-75

Tarantini A, Maitre A, Lefebvre E, Marques M, Rajhi A, Douki T (2011b) Polycyclic aromatic hydrocarbons in binary mixtures modulate the efficiency of benzo[a]pyrene to form DNA adducts in human cells. Toxicology 279:36-44

Teranishi M, Toyooka T, Ohura T, Masuda S, Ibuki Y (2010) Benzo[a]pyrene exposed to solarsimulated light inhibits apoptosis and augments carcinogenicity. Chem Biol Interact 185:411

Toyooka T, Ibuki Y (2007) DNA damage induced by coexposure to PAHs and light. Environ Toxicol Pharmacol 23:256-63

Tsuji G, Takahara M, Uchi H, et al. (2011) An environmental contaminant, benzo(a)pyrene, induces oxidative stress-mediated interleukin- 8 production in human keratinocytes via the aryl hydrocarbon receptor signaling pathway. J Dermatol Sci 62:42-49

VanRooij JG, Bodelier-Bade MM, De Looff AJ, Dijkmans AP, Jongeneelen FJ (1992) Dermal exposure to polycyclic aromatic hydrocarbons among primary aluminium workers. Med Lav 83:519-529

VanRooij JG, Bodelier-Bade MM, Jongeneelen FJ (1993) Estimation of individual dermal and respiratory uptake of polycyclic aromatic hydrocarbons in 12 coke oven workers. Br J Ind Med 50:623-32

Villard PH, Sampol E, Elkaim JL, et al. (2002) Increase of CYP1B1 transcription in human keratinocytes and HaCaT cells after UV-B exposure. Toxicol Appl Pharmacol 178:137-43

von Koschembahr A, Youssef A, Beal D, et al. (2018) Solar simulated light exposure alters metabolization and genotoxicity induced by benzo[a] pyrene in human skin. Sci Rep 8:10.1038/s41598-018-33031-8

Xia Q, Chiang HM, Yin JJ, et al. (2015) UVA photoirradiation of benzo[a]pyrene metabolites: induction of cytotoxicity, reactive oxygen species, and lipid peroxidation. Toxicol Industr Health 31:898-910

Youssef A, von Koschembahr A, Caillat S, Corre S, Galibert MD, Douki T (2018) 6Formylindolo[3,2-b]carbazole (FICZ) is a very minor photoproduct of tryptophan at biologically relevant doses of UVB and simulated sunlight. Photochem Photobiol 95:237243

Yu H, Xia Q, Yan J, et al. (2006) Photoirradiation of polycyclic aromatic hydrocarbons with UVA light - a pathway leading to the generation of reactive oxygen species, lipid peroxidation, and DNA damage. Int J Environ Res Public Health 3:348-54 


\section{TABLES}

Table 1: Viability determined by a MTT assay in skin explants and primary cultures of normal human keratinocytes exposed to SSL (2 MED), CTP and CTP-S (CTP: crude coal tar pitch extract; CTP-S: synthetic reconstitution of the PAH fraction of CTP) following different experimental protocols. An amount of CTP-S corresponding to $10 \mathrm{nmol}$ B[a]P was topically applied to the skin explants. The concentration of CTP-S and CTP in the culture medium of keratinocytes was either 0.01 or $0.1 \mu \mathrm{M}$. Skin explants originating from a same donor were used in triplicate for each condition. Keratinocytes cultured from two different skin samples (6 replicates per condition for each donor) were grown in 96-well plates for the assay. Results are \% of viability compared to untreated samples.

\begin{tabular}{|c|c|c|c|c|c|}
\hline \multicolumn{6}{|c|}{ Skin Explants } \\
\hline Control & $\begin{array}{c}\text { Positive } \\
\text { control }\end{array}$ & SSL & CTP-S 10 & SSL/CTP-S 10 & CTP-S 10/SSL \\
\hline $100 \pm 11$ & $14 \pm 2$ & $77 \pm 4$ & $73 \pm 3$ & $69 \pm 5$ & $49 \pm 5$ \\
\hline \multicolumn{7}{|c|}{ Keratinocytes } \\
\hline No SSL : & control & $\begin{array}{c}\text { CTP-S 0.01 } \\
\mu \mathrm{M}\end{array}$ & $\begin{array}{c}\text { CTP-S 0.1 } \\
\mu \mathrm{M}\end{array}$ & CTP $0.01 \mu \mathrm{M}$ & CTP $0.1 \mu \mathrm{M}$ \\
\hline & $100 \pm 6$ & $93 \pm 6$ & $88 \pm 6$ & $91 \pm 5$ & $80 \pm 5$ \\
\hline SSL/HAP : & SSL & $\begin{array}{c}\text { SSL+CTP-S } \\
0.01 \mu M\end{array}$ & $\begin{array}{c}\text { SSL+CTP-S } \\
0.1 \mu M\end{array}$ & $\begin{array}{c}\text { SSL+CTP } 0.01 \\
\mu M\end{array}$ & $\begin{array}{c}\text { SSL+CTP } 0.1 \\
\mu M\end{array}$ \\
\hline & $76 \pm 5$ & $69 \pm 4$ & $67 \pm 5$ & $67 \pm 4$ & $47 \pm 4$ \\
\hline HAP/SSL : & SSL & $\begin{array}{c}\text { CTP-S 0.01 } \\
\mu M+S S L\end{array}$ & $\begin{array}{c}\text { CTP-S 0.1 } \\
\mu M+S S L\end{array}$ & $\begin{array}{c}\text { CTP } 0.01 \\
\mu M+S S L\end{array}$ & $\begin{array}{c}\text { CTP } 0.1 \\
\mu M+S S L\end{array}$ \\
\hline & $76 \pm 5$ & $6.5 \pm 0.3$ & $2.8 \pm 0.2$ & $2.2 \pm 0.2$ & $1.2 \pm 0.1$ \\
\hline
\end{tabular}


Table 2: Increase in the expression of CYP450 genes upon exposure to PAH for 48 hours and SSL. Samples were irradiated either 1 hour before or 24 hours after the beginning of the PAH treatment (CTP: crude coal tar pitch extract; CTP-S: synthetic reconstitution of the PAH fraction of CTP). The numbers in brackets are the ratio between expression observed in skin explants treated with PAH with additional exposure to SSL and in those treated with PAH only (see Fig. 1). Results were obtained from three donors studied in triplicates and represent the mean \pm standard error. Statistical significance of the differences between irradiated and non-irradiated: $* p<0.05, * * p<0.01$.

\begin{tabular}{|c|c|c|c|}
\hline & CYP1A1 & CYP1A2 & CYP1B1 \\
\hline $\mathrm{SSL}$ & $2.5 \pm 0.4(2.1)$ & $1.8 \pm 0.3(1.7)$ & $1.7 \pm 0.3(1.5)$ \\
\hline $\mathrm{SSL}+\mathrm{B}[\mathrm{a}] \mathrm{P}-10$ & $52.1 \pm 15.3(2.5)$ & $34.6 \pm 16.6(1.5)$ & $5.5 \pm 1.1(1.6)$ \\
\hline $\mathrm{SSL}+\mathrm{CTP}-\mathrm{S}-10$ & $114.1 \pm 43.2(0.5) * *$ & $85.6 \pm 41.7(0.3) * *$ & $10.1 \pm 2.4(0.5) * *$ \\
\hline $\mathrm{SSL}+\mathrm{CTP}-10$ & $65.3 \pm 18.3(0.4) * *$ & $19.9 \pm 6.7(0.2) * *$ & $8.9 \pm 2.1(0.6)$ \\
\hline $\mathrm{B}[\mathrm{a}] \mathrm{P}-10+\mathrm{SSL}$ & $35.7 \pm 6.8(1.7)$ & $54.1 \pm 16.8(2.4)$ & $5.3 \pm 0.6(1.5)$ \\
\hline $\mathrm{CTP}-\mathrm{S}-10+\mathrm{SSL}$ & $163.5 \pm 53.7(0.7) *$ & $180.0 \pm 85.8(0.6) * *$ & $13.4 \pm 2.3(0.6) *$ \\
\hline $\mathrm{CTP}-10+\mathrm{SSL}$ & $105.5 \pm 25.9(0.6)$ & $38.0 \pm 7.9(0.3) *$ & $12.8 \pm 3.0(0.9)$ \\
\hline
\end{tabular}


Table 3: Level of BPDE-N ${ }^{2}-\mathrm{dGuo}$ in the DNA of skin explants incubated with PAH for either 24 or 48 hours, and co-exposed to SSL (CTP: raw coal tar pitch extract; CTP-S: synthetic reconstitution of the PAH fraction of CTP). The latter was applied either 1 hour before or 24 hours after the beginning of the PAH treatment. The value in brackets is the decrease in adduct formation, namely the ratio between the data obtained in the absence and the presence of an irradiation step. Results were obtained from three donors studied in triplicate and represent the mean \pm standard error. Statistical significance of the differences between irradiated and non-irradiated: $* \mathrm{p}<0.05$, ** $\mathrm{p}<0.01$.

\begin{tabular}{|c|c|c|}
\hline Treatment & 48 h post PAH & 24 h post PAH \\
\hline B[a]P-10 & $9.9 \pm 1.9$ & $3.61 \pm 0.52$ \\
\hline SSL + B[a]P-10 & $7.1 \pm 1.5(1.4)$ & $0.56 \pm 0.16(6.5)^{* *}$ \\
\hline B[a]P-10+SSL & $6.9 \pm 1.2(1.4)$ & \\
\hline CTP-S-10 & $5.4 \pm 0.8$ & $0.24 \pm 0.04$ \\
\hline SSL + CTP-S-10 & $1.4 \pm 0.3(3.8)^{* *}$ & $0.11 \pm 0.03(2.2)^{* *}$ \\
\hline CTP-S-10 + SSL & $2.5 \pm 0.5(2.1)^{*}$ & \\
\hline
\end{tabular}




\section{LEGENDS TO FIGURES}

Figure 1: Modulation of the expression of CYP genes in skin exposed for 48 hours either to 10 nmol of pure $\mathrm{B}[\mathrm{a}] \mathrm{P}$ or to solution of mixture containing $10 \mathrm{nmol} \mathrm{B}$ [a]P (CTP: raw coal tar pitch extract; CTP-S: synthetic reconstitution of the PAH fraction of CTP). Results were obtained from three donors studied in triplicates and represent the mean \pm standard error. Statistical significance of the differences: $* \mathrm{p}<0.05,{ }^{* *} \mathrm{p}<0.01$. All values were statistically different from those of the unexposed controls.

Figure 2: Time-course formation of BPDE- $\mathrm{N}^{2}$-dGuo adducts in skin explants exposed either to 10 nmol of pure $\mathrm{B}[\mathrm{a}] \mathrm{P}$ or to solution of mixtures containing $10 \mathrm{nmol} \mathrm{B}[\mathrm{a}] \mathrm{P}$ (CTP: raw coal tar pitch extract; CTP-S: synthetic reconstitution of the PAH fraction of CTP). Results were obtained from three donors studied in triplicates and represent the mean \pm standard error. Statistical significance of the difference with respect to samples exposed to pure $\mathrm{B}[\mathrm{a}] \mathrm{P}: * \mathrm{p}<0.05, * * \mathrm{p}<0.01$.

Figure 3: Level of BPDE- $\mathrm{N}^{2}$-dGuo adducts in skin exposed for 48 hours to either $1 \mathrm{nmol}$ of pure $\mathrm{B}[\mathrm{a}] \mathrm{P}$ or to solutions of mixtures containing $1 \mathrm{nmol} \mathrm{B}[\mathrm{a}] \mathrm{P}$ (CTP: raw coal tar pitch extract; CTPS: synthetic reconstitution of the PAH fraction of CTP; CTP $_{\mathrm{L}}$ : raw "light" coal tar pitch extract; CTP ${ }^{\mathrm{L}}$-S: synthetic reconstitution of the PAH fraction of CTP ${ }^{\mathrm{L}}$; PC: raw petroleum extract; PC-S: synthetic reconstitution of the PAH fraction of PC). Results were obtained from three donors and represent the mean \pm standard error. Statistical significance of the differences: $* p<0.05,{ }^{* *} p<0.01$. 
Metabolism and genotoxicity of polycyclic aromatic hydrocarbons in human

\section{skin explants: mixture effects and modulation by sunlight}

Anne von Koschembahr, Antonia Youssef, David Béa ${ }^{1}$, Etienne Bourgart, Alex Rivier, Marie Marques, Marie-Thérèse Leccia, Jean-Philippe Giot, Anne Maitre and Thierry Douki

\section{Supplementary Data}

Table S1: Composition in PAH of the mixtures used in this work.

\begin{tabular}{|c|c|c|c|c|c|c|}
\hline & \multicolumn{3}{|c|}{ Concentration in raw material $(\mu \mathrm{g} / \mathrm{g})$} & \multicolumn{3}{|c|}{ Distribution in PAH (\%) } \\
\hline Mixture & CTP & CTP & PC & CTP & CTPL & PC \\
\hline Flua & 4420 & 3412 & 0 & 16 & 43 & 0 \\
\hline Pyr & 3327 & 2160 & 19 & 12 & 27 & 5 \\
\hline B[a]A & 2306 & 146 & 35 & 8 & 2 & 10 \\
\hline Chr & 2830 & 336 & 79 & 10 & 4 & 21 \\
\hline B[j]F & 1272 & 207 & 11 & 5 & 3 & 3 \\
\hline B[e]P & 4237 & 374 & 61 & 15 & 5 & 16 \\
\hline B[b]F & 2374 & 246 & 53 & 8 & 3 & 14 \\
\hline B[k]F & 1183 & 88 & 6 & 4 & 1 & 2 \\
\hline B[a]P & 2538 & 226 & 48 & 9 & 3 & 13 \\
\hline D[ah]A & 441 & 75 & 19 & 2 & 1 & 5 \\
\hline B[ghi]P & 1244 & 362 & 26 & 4 & 5 & 7 \\
\hline IP & 1861 & 369 & 11 & 7 & 5 & 3 \\
\hline
\end{tabular}

